\title{
Mercimek (Lens culinaris Medik.)'te Topraktan ve Yapraktan Fe ve Zn Mikro Element Uygulamasının Verim ve Tanede Mikro Besin Elementi İçeriğine Etkisi
}

\author{
Doğan ŞAKAR \\ Bülent YAĞMUR \\ *Bedia KARACIL \\ Dicle Üniversitesi, Ziraat Fakültesi, Tarla Bitkileri Bölümü, Diyarbakır \\ *Sorumlu yazar e-posta (Corresponding author e-mail): krclbedia@hotmail.com
}

\begin{abstract}
Öz
Araştırmanın amacı; mercimekte topraktan ve yapraktan farklı dozlarda demir sülfat ve çinko sülfat uygulamalarının verim ve tane mikro element içeriklerine etkilerini araştırmak ve sonuçta en etkili demir ve çinko sülfat uygulama şekli ve dozunu belirlemektir. Denemeler Dicle Üniversitesi Ziraat Fakültesi Tarla Bitkileri deneme alanında 2012-2013 ve 2013-2014 yıllarında kurulmuştur. Araştırma denemeleri, rastgele bloklarda, bölünmüş parseller deneme desenine göre üç yinelemeli kurulmuştur. Ana parsellere mikro element dozları ve alt parsellere çeşitler yerleştirilmiştir. Hasat sonrasında, alt parsellerden alınan mercimek tane örneklerinde demir ve çinko analizleri, Ege Üni. Ziraat Fak., Toprak Bilimi ve Bitki Besleme Bölümünde yapıımışır. Birinci yıl, üç kırmızı mercimek çeşidi (Şakar, Fırat 87 ve Çağıl)'ne topraktan ve yapraktan farkı dozlarda demir sülfat ve çinko sülfat uygulanmış ve bazı bitkisel karakterler (çiçeklenme süresi, boy, biyolojik verim ve tane verimi) ve tanelerde $\mathrm{Fe}$ ve $\mathrm{Zn}$ içeriklerine etkileri incelenmiştir. Birinci yıl denemeleri sonucuna göre en etkili mikro element dozu ve uygulama şekli belirlenmiş̧ir. Bu uygulama, ikinci yıl altı çeşitte (Yerli Kırmızı, Tigris, Kafkas, Seyran 96, Özbek ve Çiftçi) uygulanarak verim ve tanedeki mikro element içeriği üzerinde etkileri incelenmiştir. Birinci yılsonunda, topraktan $\mathrm{Fe}$ ve $\mathrm{Zn}$ sülfat uygulamasının, tane verimine ve tane mikro element içeriğine olumlu bir etkisi saptanmamıştır. Kontrol uygulaması, mikro element uygulanan parsellere göre daha yüksek değerler vermiştir. Demir sülfatın \%0.37 dozunda yapraktan uygulaması ise biyolojik verim, tane verimi ve tanelerde demir içeriğini kontrole göre önemli şekilde artıırmıştır. Yapraktan farklı dozlarda çinko sülfat uygulaması biyolojik verimi etkilememiş, \%0.66 lık doz uygulaması tane verimini kontrole göre arttırmıştır. Genelde düşük olan tohum $\mathrm{Zn}$ içeriği, fazla farklı olmamakla birlikte, \%0.66 doz seviyesinde diğerlerinden biraz fazla çıkmıştır. Bu nedenle, demir ve çinko sülfat için yapraktan $\% 0.30$ dozunda uygulaması, çok sayıda mercimek genotipinin gözden geçirilmesi için uygun görülmüştür. 20132014 yılında, yapraktan \%0.30'luk demir sülfat ve çinko sülfat uygulaması ile altı mercimek çeşidi verim ve tanede mikro element içerikleri yönünden büyük farklılık göstermiştir.
\end{abstract}

Anahtar Kelimeler: Mercimek, demir, çinko, çeşit, doz, verim

\section{The Effects of Soil and Foliage Applications of Fe and Zn on Yield and Seed Microelement Contents in Lentil (Lens culinaris Medik.)}

\begin{abstract}
The objectives of this research were to investigate the effects of soil and foliage applications of iron and zinc sulfades on yield and seed microelement contents in lentils, and to determine an efficient evaluation technique for screening large number of lentil genotypes. The experiments were carried out in an experimental area in the Faculty of Agriculture at Dicle University, in Diyarbakır, Turkey, during the years of 2012-2013 and 2013-2014. The experimental designs were randomized complete block with split-plot organization and had three replications. The microelement doses were located in main plots and lentil varieties in sub plots within main plots. Iron and zinc analysis of the seed samples were conducted in the related laboratories of the Soil Science and Plant Nutrition Department in the Faculty of Agriculture at Agean University, in İzmir. Various doses of iron and zinc sulphades were applied to soil and foliages of three red lentil varieties (Şakar, Fırat 87 and Çağıl). Based on the results of the first year experiments, there was no any positive effects of soil applications of iron and zinc sulphade on yield and seed microelement contents. Soil microelement applications significantly reduced these characters when compared to controls. However, in foliage applications, yield and seed microelement contents became significantly higher than the controls. Foliage
\end{abstract}


application of $0.37 \%$ iron sulphade resulted in significant increases in biological yield, seed yield and $\mathrm{Fe}$ content in the seeds. But, foliage application of zinc sulphade did not cause any significant effect yield although seed yield was higher than control in $0.66 \%$ dose level. Mean zinc contents of seeds did not differ much from each other although it was slightly higher in $0.66 \%$ than the others doses. As a results of these findings, using foliar applicacation of $0.30 \%$ iron and zinc sulfade was selected as an efficient screening technique for various lentil genotypes. In 2013-2014, this technique was used to evaluate other six varieties (Yerli Kırmızı, Tigris, Kafkas, Seyran-96, Özbek and Çiftçi). There was great variation among six lentil cultivars for yield and seed microelement content.

Keywords: Lentil, Lens culinaris, Fe, Zn, varieties, dosses, yield

\section{Giriş}

Ü Ikemizde toprakların yarısının bitkilerce yarayışlı çinko yönüyle fakir olması sonucu bitkilerde çinko noksanlığı ve buna bağlı olarak bitkisel üretimde düşüşler görülmekte ve tahıla dayalı beslenmenin hâkim olduğu bölgelerimizde (Orta ve Doğu Anadolu Bölgelerimizde) bir dizi sağlık sorunları ortaya çıkmaktadır. Çinko ve diğer mikro element eksiklikleri ile ilgili sağlık sorunları özellikle gelişmekte olan ülkelerde çok daha çarpıcı boyutlara ulaşmaktadır. İnsanlarda çinko noksanlığı boy kısırlığı, ağırlık kaybı, bağışıklık sisteminin zayıflaması, seksüel olgunlaşmanın gerilmesi vb. gibi sağlık sorunları ile karşımıza çıkmakta ve olay daha ziyade çocuklarda görülmektedir (Erdal ve ark. 1998).

Toprakta yeterli miktarda çinkonun bulunması, bitkilerin mevcut çinkodan optimum düzeyde yararlanacağı anlamı taşımaz. Toprakların pH, kireç, fosfor miktarlarının yüksek olması çinkonun yarayışıı lığını önemli ölçüde geriletmekte ve bitkide çinko noksanlığı görülmesine de neden olabilmektedir (Taban ve ark. 1998).

Çinko noksanlığı genelde kireçli, kurak ve yarı kurak bölge topraklarında görülmektedir. Bitkilerde görülen çinko noksanlığı çinkolu gübrelemeyle giderilebilmektedir. Ancak burada temel sorun problemli alanlara çinkonun nasıl uygulanacağıdır. Çünkü toprağa uygulanan çinkonun yarayışlılığını sınırlandıran faktörler nedeniyle çinkodan beklenen yarar yeterince görülmemektedir. Bu nedenle çinkonun uygulamasında alternatif yollar aranmış ve yapraktan, tohumu çinkoya kaplama, toprak + yaprak gibi uygulamalar giderek yaygınlaşmıştır (Taban ve ark. 1998).

Çinko ve demir bitki, hayvan ve insanların çok düşük miktarda intiyaç duyduğu ve alınmasının kesin olarak gerekli olduğu mikro besin elementleridir.

Topraklarda yaygın olarak ortaya çıkan çinko ve demir eksikliğinin ana nedeni toprakta gerçekte bolca bulunmasın rağmen bitkilerce alınabilir formda olmamasıdır. Toprakların genellikle yüksek düzeylerde $\mathrm{pH}$, kireç ve kile sahip olması ve organik maddenin düşük olması mevcut çinko ve demirin bitkilerce alınabilirliğini sınırlamaktadır (Marschner 1995).

Dünyanın kurak ve yarı kurak bölgelerindeki kireç oranı yüksek topraklarda noksanlığı görülen en önemli mikro besin elementi çinkodur (Takkar and Walker 1993). Türkiye genelinde yapılan bir çalışmada; tarım topraklarımızın \%50'sinde (14 milyon ha) çinko noksanlığının olduğu tespit edilmiştir (Eyüpoğlu ve ark. 1994). Sağlıklı bir bitkinin yapraklarında bir kg kuru maddede en az 20 miligram çinko olmalıdır. Bu miktar 10 miligramın altına indiğinde, bitkinin büyümesinde gerileme yaprak boyunda azalma ve şeklinde bozulmalar, dolayısıyla veriminde büyük düşüşler ortaya çıkmaktadır (Çakmak ve ark. 1995).

Bu bilgiler ışığı altında yapılan araştırmada gerek bitki gerekse insan beslenmesi açısından büyük öneme sahip olan ve ülkemiz toprakların da noksanlığı hissedilen çinko $(Z n)$ ve demir (Fe) mikro elementlerinin mercimek bitkisinin gelişimi ve beslenmesi yanında verim ve verim öğeleri üzerine etkilerini belirleyerek çinko (Zn) ve demir ( $\mathrm{Fe}$ ) gübre uygulaması ile mercimek bitkisinin üretiminin ve kalitesinin artırılmas amaçlanmıştır. Mikro element yönünden zengin genitörler ortaya çıkarılarak daha sonra ki ıslah çalışmaların da bunlardan yararlanılabilecektir. Mercimekte yapılan bu çalışmayla ıslah teknolojisine, pazarlama teknolojisine, zaman içerisinde önemli etkilerinin olacağı düşünülmektedir.

\section{Materyal ve Yöntem}

$\mathrm{Bu}$ araştırma, Dicle Üniversitesi Ziraat Fakültesi Tarla Bitkileri Bölümü araştırma alanında 2012-2013 ve 2013-2014 yılları yetiştirme döneminde yürütülmüştür. 
Araştırma materyali olarak birinci yıl (20122013) üç kışlık kırmızı mercimek çeşidi (Şakar, Çağıl, Fırat-87), ikinci yıl (2013-2014) altı kışlık kırmızı mercimek çeşidi (Tigris, Seyran 96, Yerli kırmızı, Çiftçi, Özbek ve Kafkas) kullanılmıştır. Çeşitler Güneydoğu Anadolu Tarımsal Araştırma Enstitüsü Müdürlüğü'nden temin edilmiştir.

Araştırmanın birinci yılında (2012-2013), mikro elementlerin (demir ve çinko) farklı dozlarının toprak ve yaprak uygulama denemeleri olmak üzere dört deneme kurulmuştur. Denemeler, rastgele bloklar deseninde ve bölünmüş parseller deneme düzeninde 3 yinelemeli kurulmuştur. Ana parsellere mikro element dozları ve ana parseller içinde alt parsellere çeşitler yerleştirilmiştir. Çağıl, Fırat 87 ve Şakar mercimek çeşitleri 3 m uzunlukta sıralara 5'şer sıra elle ekilmiştir. Sıralar arasında $20 \mathrm{~cm}$ mesafe bırakılmış ve sıralar üzerine tohumlar 5 $\mathrm{cm}$ aralıkla ekiliştir. Demir ve çinko formülasyonları $\mathrm{FeSO}_{4} 7 \mathrm{H}_{2} \mathrm{O}$ ve $\mathrm{ZnSO}_{4} 7 \mathrm{H}_{2} \mathrm{O}$ şeklindedir. Demir mikro elementinin toprağa uygulanmasında; dekara $0,1,2,3,4$ ve $5 \mathrm{~kg}$ $\mathrm{ZnSO}_{4} 7 \mathrm{H}_{2} \mathrm{O}$ hesabıyla demir sülfat dozları (metrekareye 0, 1, 2, 3, 4 ve $5 \mathrm{~g} \mathrm{FeSO}_{4} 7 \mathrm{H}_{2} \mathrm{O}$ ) kullanılmıştır. Her ana parsel $9 \mathrm{~m}^{2}$ olduğundan, bir blokta bulunan ana parsellere $0,9,18,27$, 36 ve $45 \mathrm{~g}$ demir sülfat dozları uygulanmıştır. Dozlar, $500 \mathrm{ml}$ saf su içinde eritilmiştir. Çinko mikro elementinin toprağa uygulanmasında dekara 0, 1, 2, 3 ve $4 \mathrm{~kg} \mathrm{ZnSO} 47_{4} \mathrm{H}_{2} \mathrm{O}$ dozları (metrekareye $0,1,2,3$ ve $4 \mathrm{~g} \mathrm{ZnSO}_{4} 7 \mathrm{H}_{2} \mathrm{O}$ ) kullanılmıştır. Dozlar, her blokta bulunan beş ana parsele ekimden önce püskürtülmüştür. Birinci yıl yaprak uygulaması denemeleri, mercimek çeşitlerinin yapraklarına çiçeklenme dönemi ortasında (tane doldurma başlangıcında) uygulanmıştır. Demir uygulamasında, biri kontrol olarak $5 \mathrm{doz} \mathrm{FeSO}_{4}$ $7 \mathrm{H}_{2} \mathrm{O}(\% 0.00, \% 0.37, \% 0.75, \% 1.12$ ve $\% 1.49^{\prime}$ lik) hazırlanan çözeltiler 25.04.2013 günü yapraklara uygulanmıştır. Çözeltiler 20 litrelik plastik kovalarda hazırlanmıştır. Her uygulama başlangıcında; 16 litrelik boş kovanın içine 16 litre çeşme suyu, hesaplanan demir sülfat miktarı, $40 \mathrm{~g}$ üre ve 10 mililitre yaydırıcı yapıştırıcı ilave edildikten sonra iyice karıştırılmıştır. Her yinelemenin ilgili ana parselinde bulunan bitkilerin yapraklarına dört litrelik çözelti püskürtülmüştür. Kontrol ana parsellerinin her birine sadece 4 litre çeşme suyu püskürtülmüştür. Uygulamalar, alttaki ve üstteki yapraklar ile yaprakların alt ve üst yüzleri tamamen yıkanacak şekilde gerçekleştirilmiştir. Çinko uygulamasında, biri kontrol olarak 5 doz $\mathrm{ZnSO}_{4} .7 \mathrm{H}_{2} \mathrm{O}(\% 0.00, \% 0.33, \% 0.66, \% 0.99$ ve $\% 1.32$ 'lik) hazırlanan çözeltiler 25.04.2013 günü yapraklara uygulanmıştır. Çinko mikro elementinin yaprağa uygulanmasında diğer ayrıntılar demir sülfat uygulamasının aynısıdır. Araştırmanın ikinci yılında, altı bölge kırmızı mercimek çeşidine biri kontrol grubu olmak üzere iki doz yaprak uygulaması yapılmıştır. Denemelerden biri yapraklara demir sülfat diğeri çinko sülfat uygulaması için kurulmuştur. Altı kışlık kırmızı mercimek çeşidi; Tigris, Seyhan96, Yerli Kırmızı, Çiftçi, Özbek ve Kafkas çeşitleridir. Denemeler, rastgele bloklar deseninde ve bölünmüş parseller deneme düzeninde 3 yinelemeli kurulmuştur. Demir sülfat ve çinko sülfat hazırlanması ve uygulaması ilk yıl yaprak uygulamasında anlatıldığı gibidir. Uygulama, çiçeklenmenin ortasında 08.05.2014 tarihinde akşamüzeri güneş battıktan sonra yapılmıştır. Her doz (ana) parseline 4 litre, üç yinelemeye toplam 12 litre solüsyon püskürtülmüştür. Kontrol parsellerindeki bitkilere ise 12 litre çeşme suyu püskürtülmüştür. Araştırmaya ait veriler Tesadüf Blokları Deseninde Bölünmüş Parseller Deneme Düzenine göre JMP 5.0.1 istatistik paket programıyla değerlendirilmiş ve ortalamalar EÖF (en küçük önemli fark) veya LSD yöntemine göre gruplandırılmıştır.

\section{Bulgular ve Tartışma}

\section{Tane Verimi $\left(\mathrm{g} / 1.2 \mathrm{~m}^{2}\right)$}

2013 Yılı: Farklı demir ve çinko dozlarının yaprağa uygulanmasından elde edilen tane verimi değerleri Çizelge 1'de verilmiştir.

Farkı demir dozlarının yaprağa uygulanmasından elde edilen tane verimi değerleri $115.2 \mathrm{~g}$ ile $209.1 \mathrm{~g}$ arasında değişmiş, yaprağa demir dozu uygulaması kontrole göre tane verimini önemli şekilde arttırmıştır. En düşük tane verimi değeri $115.2 \mathrm{~g}$ ile kontrol grubundan elde edilmiştir. En yüksek tane verimi $209.1 \mathrm{~g}$ ile \%1.49 demir dozunda ortaya çıkmıştır. Yaprağa demir sülfat uygulamasında en yüksek tane verimi Şakar çeşidinde en düşük tane verimi Fırat 87 çeşidinde ortaya çıkmıştır. Çeşit $x$ demir dozu interaksiyonunun önemli bulunması çeşitler ve demir dozları arasında önemli etkileşimler olduğunu göstermiştir. Denemede en yüksek tane verimleri; Denemenin en düşük verimi kontrol grubunda Çağıl'dan gelmiştir. Kontrol dahil bütün demir sülfat doz seviyelerinde Şakar 
çeşidinin verimi diğer çeşitleri önemli şekilde geçmiştir. Şakar'dan sonra Çağıl ikinci yüksek verimli çeşit olmuştur. Fakat kontrol grubunda Fırat 87, Çağıl'ı geçmiştir. Fırat 87 ve Çağıl çeşitlerinin tane verimleri, demir dozlarından önemli şekilde etkilenmemiştir. Şakar çeşidinde ise en yüksek verim \%0.37 ve \%1.2 demir dozlarından sağlanmıştır.

Farklı çinko dozlarından elde edilen tane verimi değerleri $73.75 \mathrm{~g}$ ile $173.2 \mathrm{~g}$ arasında değişmiştir. Yaprağa çinko uygulamasında, çeşitlere ait tane verimi değerleri $67.89 \mathrm{~g}$ ile $184.4 \mathrm{~g}$ arasında değişmiştir. En yüksek tane verimi değeri Şakar çeşidinden alınmıştır. Çeşit $x$ çinko doz interaksiyonu önemli bulunmuş yani çeşitler ve dozlar arasında önemli etkileşimler ortaya çıkmıştır. En yüksek tane verimleri Şakar çeşidinde $279 \mathrm{~g}$ ve $314 \mathrm{~g}$ ile $\% 0.66$ ve \%0.99 çinko dozlarının uygulanmasından ortaya çıkmıştır.

Şakar çeşidi, kontrol dâhil bütün çinko dozlarında en verimli çeşit olmuş ancak \%0.66 ve üzerindeki dozlarda verim farkı önemli çıkmıştır. Fırat 87 ve Çağıl çeşitlerinde çinko doz seviyeleri arasında önemli bir fark çıkmamıştır. Şakar ise $\% 0.66$ ve $\% 0.99$ çinko seviyelerinde en verimli olmuştur

2014 Yılı: Yaprağa çinko ve demir uygulamasından elde edilen tane verimi (g) ortalama değerleri ve oluşan gruplar Çizelge 2'de verilmiştir.

Farklı çinko dozlarından elde edilen tane verimi değerleri $82.36 \mathrm{~g}$ ile $126.24 \mathrm{~g}$ arasında değişmiş ve $\% 0.30$ çinko sülfat uygulaması kontrole göre tane verimini önemli ölçüde artırmıştır. En yüksek tane verimi değeri $126.24 \mathrm{~g}$ ile $\% 0.30$ çinko sülfat dozundan, en düşük tane verimi değeri ise 83.36 gile kontrol grubundan elde edilmiştir. Yaprağa çinko uygulamasında, çeşitlere ait tane verimi değerleri $73.88 \mathrm{~kg} / \mathrm{da}$ ile $153.0 \mathrm{~kg} / \mathrm{da}$ arasında değişmiştir. En yüksek tane verimi Çiftçi çeşidinde, en düşük tane verimi ise Yerli kırmızı, Özbek ve Seyran 96 çeşitlerinde saptanmıştır. Çeşit $x$ çinko doz interaksiyonunun önemli çıkması, çeşitlerin

Çizelge 1. 2013 yılı yaprağa demir ve çinko uygulamasından elde edilen tane verimi (g/parsel) ortalama değerleri ve oluşan grupları

Table 1. Seed yield (g/plot) averages and groups of Fe znd Zn foliage applications in 2013

\begin{tabular}{|c|c|c|c|c|c|c|c|c|c|}
\hline \multicolumn{5}{|c|}{ Vapıak Fe } & \multicolumn{5}{|c|}{ Yapıak Zו } \\
\hline & F॥त 87 & Şakal & Gaर̃गI & out. & & F॥तt 87 & ફ̧akal & Gaţןl। & out. \\
\hline D & I08.Ie-l) & I848c cle & $52.7 \mathrm{Dh}$ & 115. & D & $47.43 \mathrm{~g}$ & ID8 3bc & $65.541 \mathrm{bc}$ & $73.751)$ \\
\hline 0.37 & $97.77 \mathrm{tgh}$ & $3569 a$ & $13680 \mid-y$ & |97.|al) & 0.33 & $54.53 \mathrm{c}$ & $98.13 \mathrm{bc}$ & $71.151) \mathrm{c}$ & $748 \mathrm{Ib}$ \\
\hline 0.75 & 77.07gli & $220.8 \mathrm{bc}$ & $134.7(1-1)$ & $144.2 \mathrm{bc}$ & 0.66 & $68.67 \mathrm{bc}$ & $278.7 \mathrm{a}$ & $90.57 \mathrm{bc}$ & $146 \mathrm{Da}$ \\
\hline 1.12 & $86.57 \mathrm{glh}$ & $315.8 \mathrm{a}$ & $174 s-1$ & |92. Ial) & 0.99 & $1 \mathrm{ID} .2 \mathrm{bc}$ & $3140 a$ & $95.27 \mathrm{bc}$ & $1732 \pi$ \\
\hline 1.40 & $117.7 \mathrm{e}-11$ & 2992 al) & $2 \mathrm{ID} .3 \mathrm{col}$ & $209 . a$ & 132 & $58.60 \mathrm{Dg}$ & 122 9l) & $64.38 \mathrm{bc}$ & $8|95|)$ \\
\hline out. & $97.44 \mathrm{c}$ & $275 \mathrm{a}$ & $|4| .71)$ & & oit. & 67.8913 & 184.4ה & 77.3813 & \\
\hline LSD & \multicolumn{4}{|c|}{ IInt: $81.47^{x x} ; 002: 61.15^{x x}$} & LSO & \multicolumn{4}{|c|}{ Ģȩ̧it: $36.40^{x x} ;$ 002: $36.98^{x x}$} \\
\hline
\end{tabular}

Aynı harflerle gösterilen ortalamalar arasında istatistiki olarak fark yoktur.

Averages followed by same letter are not statistically different

Çizelge 2. 2014 yılı yaprağa çinko ve demir uygulamasından elde edilen tane verimi (g) ortalama değerleri ve oluşan gruplar

Table 2. Seed yield (g) averages and groups of Fe znd Zn foliage applications in 2014

\begin{tabular}{|c|c|c|c|c|c|c|c|}
\hline \multicolumn{4}{|c|}{ Va|jık Zn } & \multicolumn{4}{|c|}{ Yapak Fe } \\
\hline & Konthol & $48 \Omega$ & Oit. & & Kontol & $48 \Omega$ & Dit. \\
\hline $\begin{array}{l}\text { Clittpl } \\
\text { |cakas } \\
\text { özlyek }\end{array}$ & $\begin{array}{l}\text { I I I.4cd } \\
98.33 \mathrm{cle} \\
65.42 \mathrm{tg}\end{array}$ & $\begin{array}{l}\text { I94.6a } \\
\text { I6D.Dl) } \\
83.49 e t g\end{array}$ & $\begin{array}{l}\text { I53.Da } \\
\text { I29.3al) } \\
74.46 \mathrm{a}\end{array}$ & $\begin{array}{l}\text { Clityl } \\
\text { |ckkas } \\
\text { bzloek }\end{array}$ & $\begin{array}{l}112.6 \mathrm{cl} \\
97.17 \mathrm{cle} \\
74.05 \mathrm{det}\end{array}$ & $\begin{array}{l}325.0 \mathrm{a} \\
214.7 \mathrm{a} \\
88.15 \mathrm{cle}\end{array}$ & $\begin{array}{l}2188 \mathrm{a} \\
1559 \mathrm{a} \\
81.10 \mathrm{le}\end{array}$ \\
\hline $\begin{array}{l}\text { Seydali-96 } \\
\text { Thyוs }\end{array}$ & $\begin{array}{l}62 \mathrm{DGg} \\
98 \mathrm{D} 6 \mathrm{le}\end{array}$ & $\begin{array}{l}99.790 \mathrm{e} \\
130.5 \mathrm{~g}\end{array}$ & $\begin{array}{l}80.93 \mathrm{a} \\
114.3 \mathrm{~b}\end{array}$ & $\begin{array}{l}\text { Seyal - } 96 \\
\text { Thyis }\end{array}$ & $\begin{array}{l}91.46 \text { cle } \\
99.1 \text { icle }\end{array}$ & $\begin{array}{l}\text { ID2.3cle } \\
262 \text {.Dls }\end{array}$ & $\begin{array}{l}96.88 \mathrm{dl} \\
\mathrm{I} 8 \mathrm{D} . \mathrm{bl}\end{array}$ \\
\hline $\begin{array}{l}\text { Velll |oimzi } \\
\text { Dit. }\end{array}$ & $\begin{array}{l}58.59 \mathrm{j} \\
82.36 \mathrm{~b} \\
\end{array}$ & $\begin{array}{l}89.1 \text { Bolet } \\
126.24 \mathrm{~A}\end{array}$ & $73.88 \mathrm{a}$ & $\begin{array}{l}\text { Yeill loimzl } \\
\text { Out. }\end{array}$ & $\begin{array}{l}47.521 \\
83.85 \mathrm{l}\end{array}$ & $\begin{array}{l}92.78 \text { cle } \\
180.82 \text { a }\end{array}$ & $70.15 \mathrm{e}$ \\
\hline LSD & \multicolumn{3}{|c|}{ Cestit: $\left.25.0\right|^{x}:$ int: $2593^{x}$ : Doz: ${ }^{x}$} & LSD & \multicolumn{3}{|c|}{ Cesit: $20.46^{x x}$ int: $28.93^{x x}$, Doz: } \\
\hline
\end{tabular}

Aynı harflerle gösterilen ortalamalar arasında istatistiki olarak fark yoktur.

Averages followed by same letter are not statistically different 
tane verimlerinin doz uygulamalarından farklı şekilde etkilendiğini göstermiştir. \%0.30 çinko uygulamasında en yüksek verim Çiftçi çeşidinden (194.6 g) elde edilmiş ve bunu Kafkas $(160 \mathrm{~g})$ ikinci sırada izlemiştir. Kontrol parsellerinde ise $111.4 \mathrm{~g}$ ile Çiftçi, ardından Kafkas (98 g) ve Tigris ( $98 \mathrm{~g}$ ) en verimli grubu oluşturmuştur.

Yüzde 0.30 demir uygulanan ve demir uygulanmayan parsellerde elde edilen tane verimi değerleri $86.85 \mathrm{~kg} / \mathrm{da}$ ile 180.82 $\mathrm{kg} /$ daarasında değişmiş ve $\% 0.30$ luk demir sülfat uygulaması tane verimini önemli ölçüde arttırmıştır. Kontrol grubu $86.85 \mathrm{~g}$ ile en düşük, 0.30 'luk demir sülfat uygulaması ise $180.82 \mathrm{~g}$ ile en yüksek tane verimi değeri vermiştir. Yaprağa demir uygulamasında, çeşitlere ait tane verimi değerleri $70.15 \mathrm{~kg} / \mathrm{da}$ ile $218.8 \mathrm{~g}$ arasında değişmiştir. En yüksek tane verimi Çiftçi çeşidinde en düşük tane verimi değeri Yerli kırmızı çeşidinde olduğu saptanmıştır. Çeşit $x$ demir doz interaksiyonu önemli bulunması denemede demir uygulanan ve uygulanmayan parsellerde çeşitlerde verim sıralamasının değiştiğini göstermiştir. Demir uygulanan parsellerde Çiftçi çeşidi $325 \mathrm{~g}$ ile diğer çeşitleri önemli şekilde geride bırakmıştır. Kontrol parsellerinde Çiftçi, Tigris, Kafkas ve Seyran 96 çeşitlerinin tane verimleri arasında önemli bir fark çıkmamış fakat bunların verimleri Özbek ve Yerli Kırmızı çeşitlerini geçmiştir.

Hem çinko hem de demir uygulamasının tane verimini arttırdığı saptanmıştır. Bulgularımız Dawood and El Far (1994), Gagwar and Singh (1994), Sadeghi and Noorhosseini (2014), Khalil and Khalifa (1991), Singh and Bhatt (2013)'nın bildirdikleri ile benzer bulunmuştur.

Nitekim Dawood and El Far (1994) Mercimeğe yapraktan uygulanan mikro ve makro besin elementlerinin, Gagwar and Singh (1994) yapraktan uygulanan çinkonun, topraktan uygulanan çinkoya göre birim alan tane verimin artırdığını, Sadeghi and Noorhosseini (2014) demir + çinko ve yalnız demir uygulamasının verimi kontrole göre $\% 37.71$ ile \%27.12 oranında arttırdığını bildirmişlerdir.

Ayrıca, Khalil and Khalifa (1991) yapraktan azot, fosfor ve potasyum uygulamasının mercimekte birim alan tane verimini \%58 oranında artırdığını, azot, fosfor ve potasyuma ilaveten çinko mangan, demir ve bakırında eklenmesiyle verim artışının devam ettiğini bildirmektedirler. Singh and Bhatt (2013) yaprağa uygulanan çinkonun $(\% 0.08$ uygulamasından) maksimum tane verimi $(1238.6 \mathrm{~kg} / \mathrm{ha}) \% 0.04$ çinko uygulamasından, en düşük $1063.1 \mathrm{~kg} / \mathrm{ha}$ olarak kontrol grubundan elde edildiğini bildirmişlerdir.

\section{Sonuç}

Genelde düşük olan tohum $\mathrm{Zn}$ içeriği, fazla farklı olmamakla birlikte, \%0.66 doz seviyesinde diğerlerinden biraz fazla çıkmıştır. $\mathrm{Bu}$ nedenle, demir ve çinko sülfat için yapraktan $\% 0.30$ dozunda uygulaması, çok sayıda mercimek genotipinin gözden geçirilmesi için uygun görülmüştür. 2013-2014 yılında, yapraktan \%0.30'luk demir sülfat ve çinko sülfat uygulaması ile altı mercimek çeşidi verim ve tanede mikro element içerikleri yönünden büyük farklılık göstermiştir.

\section{Teşekkür}

Bu araştırma Dicle Üniversitesi DUBAP 12ZF-97 nolu proje kapsamında DUBAP tarafından desteklenmiştir.

\section{Kaynaklar}

Bayraklı F, 1983. Toprak Verimliliği ve Bitki Besleme. O.M.Ü. Ziraat Fak. Yay. Ders Notları No: 2, Samsun

Dawood, RA, Elfar IA, 1994. Response of organic and quality characteristics of lentil to foliar microelements. Assiut-Journal-Sciences, 25(3): 143-154

Gangwar KS, Singh NP, 1994. Studies on zinc nutrient on lentil in relation to dry matter accumulation, yield and N, P uptake. Indian Journal of Pulse Research, 7: 133-353

Khalil NA, Khalita R, 1991. Response of lentil (Lens culinaris Medic.) growth and yield to macro and micro nutrient application. Bulletin of Faculty of Agriculture, Unv. of Cairo, 42: 3, 701 Giza, Egypt

Sadeghi SM, Noorhosseini SA, 2014. Evaluation of foliar application effects of $\mathrm{Zn}$ and $\mathrm{Fe}$ on yield and its components of lentil (Lens culinaris, Medik), Iran. Indian Journal of Fundamental and Applied Life Sciences, 4(2): $220-225$

Singh AK, Bhatt BP, 2013. Effect of Foliar application of zinc on growth and seed yeild of late - sown lentil (Lens culinaris). The Indian Journal of Agricultural Sciences, 83(6): 622-626 